\title{
Latinum cedens. Le français et le latin langues de spécialité au Moyen Âge. Édité par Stéphane Marcotte et Christine Silvi
}

\section{Maria Colombo Timelli}

\section{(2) OpenEdition Journals}

Édition électronique

URL : http://journals.openedition.org/studifrancesi/4282

DOI : 10.4000/studifrancesi.4282

ISSN : 2421-5856

Éditeur

Rosenberg \& Sellier

\section{Édition imprimée}

Date de publication : 1 septembre 2016

Pagination : 298-299

ISSN : 0039-2944

\section{Référence électronique}

Maria Colombo Timelli, «Latinum cedens. Le français et le latin langues de spécialité au Moyen Âge. Édité par Stéphane Marcotte et Christine Silvi », Studi Francesi [En ligne], 179 (LX | II) | 2016, mis en ligne le 01 septembre 2016, consulté le 18 septembre 2020. URL : http://journals.openedition.org/ studifrancesi/4282 ; DOI : https://doi.org/10.4000/studifrancesi.4282

Ce document a été généré automatiquement le 18 septembre 2020.

\section{cc) $($ ) $\ominus$}

Studi Francesi è distribuita con Licenza Creative Commons Attribuzione - Non commerciale - Non opere derivate 4.0 Internazionale. 


\title{
Latinum cedens. Le français et le latin langues de spécialité au Moyen Âge. Édité par Stéphane Marcotte et Christine Silvi
}

\author{
Maria Colombo Timelli
}

\section{RÉFÉRENCE}

Latinum cedens. Le français et le latin langues de spécialité au Moyen Âge. Édité par Stéphane MARCOTTE et Christine SILVI, Paris, Champion, 2014, «Colloques, congrès et conférences. Sciences du Langage, histoire de la langue et des dictionnaires» 14, 390 pp.

1 Le panoramique linguistique de la France médiévale est on ne peut plus nuancé: le bilinguisme latin-français, tout particulièrement, mérite des investigations ultérieures dans la mesure où l'avancée du second au détriment du premier se fit de manière non linéaire, en fonction des champs disciplinaires, voire des textes et de leurs destinataires. Ce beau recueil d'articles se propose comme une réflexion organisée par domaines du savoir: Bible, médecine, sciences de la nature, droit, sont tour à tour appréhendés dans des contributions denses, dont la longueur même permet d'aborder les différents sujets de façon approfondie.

2 Pour ce qui est de la Théologie biblique, titre de la première partie, Xavier-Laurent SALVADOR s'occupe de la Bible historiale, première traduction de la Bible en prose française (1295), qui intègre dans des passages signalés comme 'Glose' le savoir scientifique transmis par l'Historia Scholastica de Petrus Comestor: en cela, l'œuvre de Guyart-des-Moulins peut être définie une des "premières encyclopédies générales» en langue française (p.42) (Le discours scientifique et didactique à l'ouvre dans la Bible historiale de Guyart-des-Moulins, pp. 27-43). 
3 Le domaine de la médecine (deuxième partie) a attiré d'abord l'attention d'Isabelle VEDRENNE-FAJOLLES: en dépouillant un corpus de quatre textes médicaux composés entre 1240 et 1314, elle relève la présence du latin dans les titres d'œuvre, dans les titres des divisions internes, ainsi que dans la terminologie utilisée; si le transfert vers le français prévaut, le latin demeure régulièrement présent même dans les œuvres à visée divulgatrice (Médecine médiévale et plurilinguisme: de la pertinence des facteurs génériques, pp. 45-82). Sylvie BAZIN-TACCHELLA analyse quant à elle le manuscrit Nancy, B.M. 269 (seconde moitié du XIve siècle), qui contient les versions latine et française d'un même réceptaire; comme le prouve l'A., la traduction s'est faite du français en latin, ce qui pose la question de la fonction de chaque langue dans la diffusion du savoir médical pratique. Une édition synoptique du réceptaire est publiée en annexe (Disparition ou maintien du latin dans la littérature médicale pratique: le cas des antidotaires et des réceptaires médicaux en français (XIV ${ }^{e}-\mathrm{XV}$ siècles, pp. 83-114).

4 La troisième section est consacrée aux sciences de la nature. Sur la base d'un corpus de six textes des $\mathrm{XII}^{\mathrm{e}}$ et $\mathrm{XIII}^{\mathrm{e}}$ siècles, Cécile LE CORNEC-ROChELoIs mène une étude sur les dénominations de quelques animaux en latin et/ou en français, en essayant surtout de comprendre les raisons de la fixation d'une nomenclature à partir d'un certain nombre de doublets (assida/autruche, cète/baleine, castor/bièvre, mustelle/belette) (Nommer les animaux en latin dans les encyclopédies et les bestiaires en français: savoir ou ignorance?, pp. 117-138). Christine SILVI s'interroge sur les termes utilisés dans Placides et Timeo et dans le Livre des propriétés des choses de Jean Corbechon pour désigner la Terre. Vis-à-vis de la diversité des terminaisons latines remontant à Isidore, le compilateur s'efforce de rendre la complexité des signifiés par un nombre élevé de signifiants, alors que le traducteur de Barthélemy l'Anglais opte pour des périphrases qui expliquent et justifient les étymologies en cause (Comment nommer la terre en français? De quelques signifiants utilisés par les encyclopédistes médiévaux, pp.139-168). Fleur VIGNERON étudie une traduction anonyme (1373) du Liber ruralium commodorum de Pietro de' Crescenzi, et en particulier les résidus en latin dans le manuscrit 10227 de Bruxelles (1420-1430) et dans des témoins plus récents, jusqu'en 1540. Elle essaie de comprendre les raisons de la permanence des dénominations latines et bilingues dans la copie de la KBR et de leur disparition progressive (Les limites $d u$ français pour traduire un traité d'agriculture: le cas $d u$ "Livre des ruraulx prouffis du labour des champs" de Pierre de Crescens, pp. 169-183).

5 La partie consacrée au droit, la plus consistante du volume, compte deux articles. Étudiant un corpus de sept traductions anonymes du XIII ${ }^{\mathrm{e}}$ siècle du Corpus juris civilis, Hélène BIU constate que la terminologie juridique est essentiellement française: non seulement le recours à l'emprunt est limité, les traducteurs adoptant plutôt des équivalents tirés du droit coutumier ou des mots du langage courant, mais le vocabulaire s'avère constant et stable d'une traduction à l'autre, avant d'être profondément relatinisé au siècle suivant. Hélène Biu s'interroge aussi sur le public auquel ces traductions étaient destinées: bourgeois, marchands, notaires, avocats, étudiants en droit civil, des utilisateurs diversifiés unis par la nécessité d'accéder à ces textes dans leur langue maternelle (La langue d'oil est-elle apte à dire le droit? Réflexions sur l'élaboration du lexique juridique français, pp. 187-240, avec une importante bibliographie finale et, en annexe, des extraits des traductions objet de l'analyse). La longue contribution de Stéphane MARCOTTE constitue une sorte de bilan des études dans le domaine: elle vise notamment à reconnaître les raisons qui ont déterminé le maintien du latin comme langue du droit jusqu'au $\mathrm{xVI}^{\mathrm{e}}$ siècle, raisons complexes parmi lesquelles 
les facteurs purement linguistiques sont finalement secondaires vis-à-vis des changements idéologiques et sociologiques de la France entre le xiII ${ }^{e}$ siècle et le siècle de la Renaissance (Droit et langue française en France au Moyen Âge: essai de synthèse sur une relation multi-paradoxale, pp. 241-356, dont 25 pages de bibliographie).

6 De précieux Index complètent le volume: auteurs et œuvres anonymes jusqu'au XviII ${ }^{\mathrm{e}}$ siècle, chercheurs et éditeurs, lieux, notions, mots latins et grecs, mots français. 